\title{
CO Adsorption on Mo(110) Studied Using Thermal Desorption Spectroscopy (TDS) and Ultraviolet Photoelectron Spectroscopy (UPS)
}

\author{
Taek-seung Yang, Hae-geun Jee, Jin-Hyo Boo, Young Dok Kim, ${ }^{*}$ and Soon-Bo Lee ${ }^{\star}$ \\ Department of Chemistry, Sunghumkwan Cniversity, Stmon, Gleonggi $4+0-7+6$, Korea \\ 'E-mail: vdkimolòskkuedu andxpslessóoskku.edu \\ Recerved Harch 25, 2009, Accepted Hav 4, 2009
}

\begin{abstract}
This study exannined the adsortion of CO on a Mo( 110 ) surface by Themal Desorption Spectroscopy (TDS) and synchrotron-radiation based photoemission spectroscopy (SRPES). CO desorption was observed at approximately $400 \mathrm{~K}(\alpha-\mathrm{CO})$ and $>900 \mathrm{~K}(\beta-\mathrm{CO})$. When $\mathrm{CO}$ was exposed to $\mathrm{Mo}(\mathrm{I} 10)$ at $100 \mathrm{~K}$, it showed a tilted structure at low CO coverage and a vertical structure after saturation of the tilted $C O$. After heating the CO-precovered sample to 900 $\mathrm{K}$, a broad peak at $12 \mathrm{eV}$ below the Fermi level was identified in the valence level spectra, which was assigned to either the $4 \sigma$-molecular orbital of $\mathrm{CO}$, or $2 \mathrm{~s}$ of dissociated carbon. TDS results of the $\beta$-CO showed a first order desorption. These results are in a good agreement with the observations of $\mathrm{CO}$ adsorption on $\mathrm{W}(1 \mathrm{l} 10)$ surfaces.
\end{abstract}

Key Words: Chemisorption, CO, Mo(110). Photoemission spectroscopy

\section{Introduction}

The elementary steps in heterogeneous cataly sis consist of the chemisorption of gas molecules on solid surfaces. ${ }^{1,2}$ Understanding of the chemisorption of reactants on the atomic scale is essential for examining the mechanism of heterogeneously catalyzed reactions. CO chemisorption on transition metal surfaces has been studied extensively over the last 50 years due to its structural simplicity and technological importance in heterogeneous catalysis. ${ }^{3 .+}$

In particular, the $\mathrm{CO}$ adsorption structure on $\mathrm{W}$ and $M$ Mo has been debated for a considerable time. The dissociative and non-dissociative chemisorption of $\mathrm{CO}$ on both surfaces have been suggested using a variety of experimental and theoretical methods ${ }^{3,-1-1}$ Experimentally identifying the dissociative chemisorption of $\mathrm{CO}$ on a solid surface is not trivial. Electron stimulated desorption (ESD) and Thermal Desorption Spectroscopy (TDS) are useful in obtaining information about adsorbate geometries: however, these methods are often regarded as rather destructive techniques providing only indirect information. ${ }^{5-13}$ Vibrational spectroscopy, such as high-resolution electron energy loss spectroscopy (HREELS) and infra-red absorption spectroscopy (IRAS). can be useful but the selection nules prohibit the detection of some molecular stnictures. e.g. it is difficult to observe molecularly bound $\mathrm{CO}$ placed parallel to the surface ${ }^{31 \cdot .23}$ Ultraviolet photoelectron spectroscopy (UPS). X-ray photoelectron spectroscopy (XPS) and Auger-electron spectroscopy (AES) can also provide important information on chemisorption geometry of $\mathrm{CO}$ on the surface ${ }^{14-i 03-23}$ A combination of surface analysis techniques is required to fully understand the chemisorptions structure of $\mathrm{CO}$.

Previous studies on $\mathrm{CO}$ chemisorptions on $\mathrm{W}(110)$ in our group suggested that $\mathrm{CO}$ is bound molecularly in a tilted form at low $\mathrm{CO}$ coverage at $100 \mathrm{~K}$. and forms a vertically chemisorbed structure after saturation of the tilted stnicture ${ }^{.3 .24}$ The vertical $\mathrm{CO}$ desorbs below $400 \mathrm{~K}$. whereas the tilted one desorbs at above $900 \mathrm{~K} .^{3 . .24}$ Most of the previous studies suggested a dissociative cheimsorption of $\mathrm{CO}$ on $\mathrm{W}(110)$ above $400 \mathrm{~K}$ : however a first order desorption kinetics was found for the $\beta$-state (desorption state above $900 \mathrm{~K}$ ) of $\mathrm{CO}$, which does not reconcile associative desorption of dissociated $C$ and $\mathrm{O}$.

This study examined $\mathrm{CO}$ adsorption on $\mathrm{Mo}(110)$ using synchrotron-radiation based photoemission spectroscopy (SRPES) with a range of photon energies. The adsorption properties of $\mathrm{CO}$ on $\mathrm{Mo}(110)$ and $\mathrm{W}(110)$ surfaces are almost identical. In particular, the first order desorption for the $\beta-\mathrm{CO}$ was also found on $\mathrm{Mo}(110)$ surfaces. In order to clarify origin of the first order desorption of $\beta-\mathrm{CO}$ on both $\mathrm{W}$ and Mo surfaces. further studies should be performed

\section{Experimental}

The experinents were carried out in an ultrahigh vacuum (UHV) system with a base pressure of $1 \times 10^{161}$ torr equipped for X-ray photoelectron spectroscopy (XPS). low energy electron diffraction (LEED) and quadrupole mass spectroscopy (QMS).

The Mo(110) samples were cleaned by a thermal treatment at $1700 \mathrm{~K}$ under an $\mathrm{O}_{2}$ atmosphere at $2 \times 10^{-8}$ torr. and heated to $2300 \mathrm{~K}$. This procedure was repeated until no impurities could be observed by LEED and XPS. The sample temperature was measured using a $C$-type thermocouple spot-welded on its side. For the TDS experiments. a heating rate of $6 \mathrm{~K} / \mathrm{s}$ was used. which was controlled using a programmed integral differential (PID) controller. The sample was cooled using a He-cryogenic sy stem connected to the sample using a $\mathrm{Cu}$ wire. For $C O$ chemisorption, the UHV chamber was backfilled with $\mathrm{CO}$.

The valence band spectra were collected at the Pohang Accelerator Laboratory (beam line 2Bl). For the photoenussion experiments in Pohang. the analyzer was placed normal to the sample surface. and the angle between the synchrotron 
radiation and analyzer aperture was $45^{\circ}$. P-polarized light with different photon energies was used to collect the valence band spectra.

\section{Results and Discussion}

Valence band spectra. In order to shed light on the adsorption structures of $\beta-\mathrm{CO}$ on $\mathrm{Mo}(110)$ surfaces. the valence band spectra of clean and $\mathrm{CO}$-covered Mo( 110$)$ surfaces were collected using a range of photon energies (Fig. I and 2). For the clean Mo(110) surface. the valence band spectra changed significantly as a function of the photon energy. The maximum intensity of the Mo-4d bands was observed at a photon energy of $55 \mathrm{eV}$. The td-peak intensity decreased gradually with increasing and decreasing photon energy from $55 \mathrm{eV}$. $\mathrm{CO}$ induced features could be observed when the Mo(110) surface was exposed to $5.0 \mathrm{~L}$ (Langmuir $\mathrm{IL}=10^{-5}$ torr $\times \mathrm{sec}$ ) of $\mathrm{CO}$ at $100 \mathrm{~K}$. A broad feature between $6.8 \mathrm{eV}$ below the Fermi level, and another state at $10.7 \mathrm{eV}$ was observed after $\mathrm{CO}$ adsorption. which were assigned to the $(1 \pi+5 \sigma)$ and $4 \sigma$. respectively. ${ }^{26-310}$ The $\mathrm{CO} 4 \sigma$-peak showed its maximum intensity at a photon energy of $55 \mathrm{eV}$. whereas the peak at $7.9 \mathrm{eV}$ corresponding to the $5 \sigma-5$ tate of $\mathrm{CO}$ at $45 \mathrm{eV}$. The $5 \sigma-5$ tate at $7.9 \mathrm{eV}$ decreased in intensity with increasing photon energy from 45 eV. whereas the $1 \pi$-peak increased. The $1 \pi$ - and $5 \sigma$-states. which are located closely energetically can be discriminated using a variety of photon energies.

In order to shed light on the coverage-dependent change in the electronic structure of $\mathrm{CO}$ on $\mathrm{Mo}(110)$. the valence band spectra were collected from CO-covered Mo(110) surfaces with various $\mathrm{CO}$ coverages (Fig. 3). $\mathrm{CO}$ was adsorbed at 100 $\mathrm{K}$. and a photon energy of $80 \mathrm{eV}$ was used to collect the valence band spectra. As mentioned above. the adsorption of $\mathrm{CO}$ indices the appearance of peaks at approximately $11 \mathrm{eV}$ and 6-8 $\mathrm{eV}$ below the Fermi level. A close inspection of the $4 \sigma-5$ tate shows that there should be two components in the $+\sigma$-state of $\mathrm{CO}$ (one centered at 10.6 and the other at $11.4 \mathrm{eV}$ ). At lower $\mathrm{CO}$ coverage. only the $11.4 \mathrm{eV}$-peak was observed. whereas the $10.6 \mathrm{eV}$-peak increased in intensity after saturation of the peak centered at $10.6 \mathrm{eV}$. A similar result was previously observed for $\mathrm{CO}$ chemisorption on $\mathrm{Cr}$ and $\mathrm{W}$ surfaces at similar temperatures. In these cases, it was concluded that the $11.4 \mathrm{eV}$ peak should correspond to the $\mathrm{CO}$ molecules tilted away from the direction nomal to the surface. whereas the $10.6 \mathrm{eV}$-peak should correspond to the vertical $\mathrm{CO}^{73,74.31 .32}$ It is possible that $\mathrm{CO}$ should be tilted at lower coverage. whereas vertical $\mathrm{CO}$ forms at higher coverage. The higher binding energy of the $4 \sigma$-state of the tilted $\mathrm{CO}$ with respect to that of the vertical one is also supported by theoretical calculations. ${ }^{33,34}$

In previous studies on CO chemisorption on W(110), it was reported that the vertical $\mathrm{CO}$ desorbs below $400 \mathrm{~K}$. whereas the tilted one transforms to a "lying-down' species or dissociated $C$ and $O$ upon heating. ${ }^{23-4}$ In order to shed light on the $\mathrm{CO}$ adsorption properties on $\mathrm{Mo}(110)$ in the $\beta$-state, the $\mathrm{CO}$ precovered sample was heated to $900 \mathrm{~K}$. and the valence band spectra were collected using a range of photon energies (Fig. 4). Using a photon energy of $55 \mathrm{eV}$, the broad feature at $12 \mathrm{eV}$ was assigned to the $4 \sigma$-state of $\mathrm{CO}$. or $2 \mathrm{~s}$ of dissociated $\mathrm{C}$. i.e.

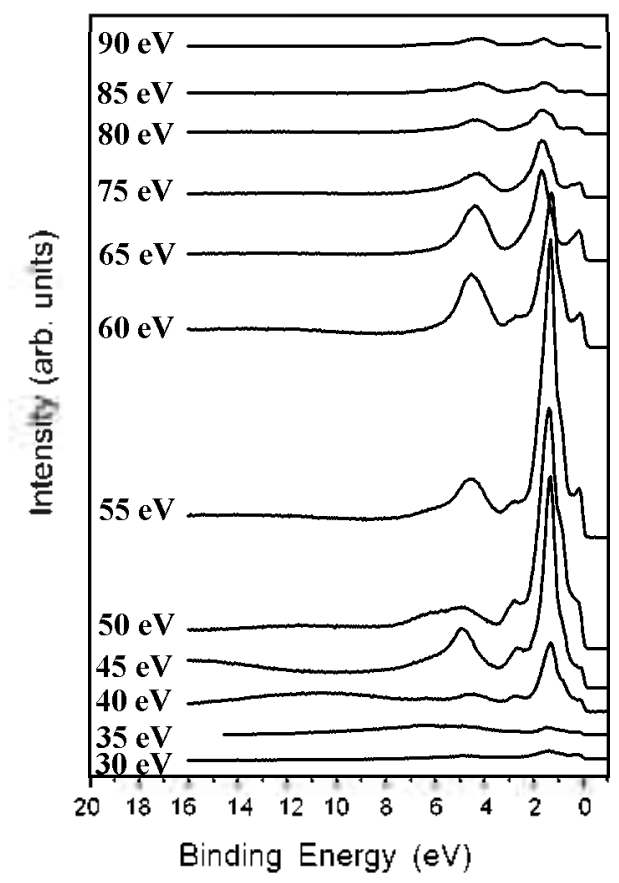

Figure 1. Valence band spectra of clean Mo(110) surfaces using a range of photon energies. The photon energies used to take the spectra are given in the figure.

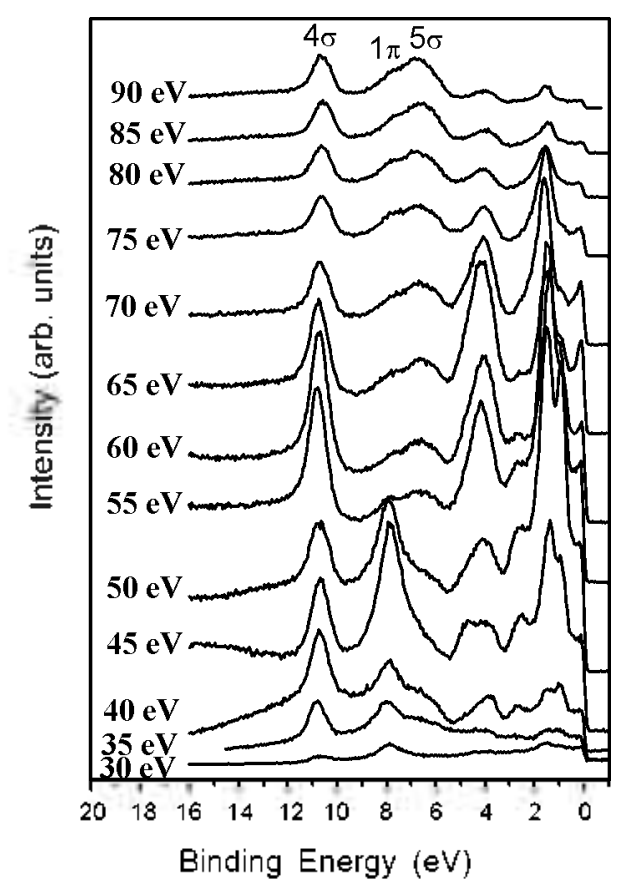

Figure 2. Valence band spectra of $\mathrm{CO}$ covered Mo( 110$)$ surfaces using various photon energies. The samples were exposed to $50 \mathrm{~L}$ of $\mathrm{CO}$ at $100 \mathrm{~K}$. The photon energies used to take the spectra are given in the figure.

from the valence band spectrum. it is not clear. whether $\mathrm{CO}$ was dissociated or not upon heating to $900 \mathrm{~K}$. It is worth mentioning that a sintilar result was found in a previous study, and in combination with $\mathrm{C}$ ls level spectra. it was concluded that CO should be dissociated above $400 \mathrm{~K}$.

TDS results. Fig. 5 shows the TDS spectra of $\mathrm{CO}$ with 


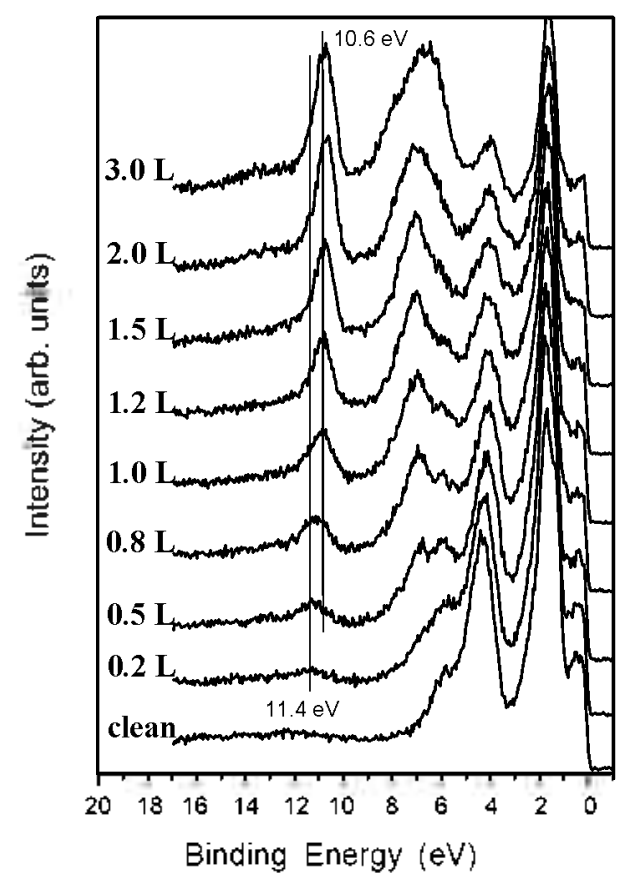

Figure 3. Valence band spectra of $\mathrm{Mo}(110)$ after stepwise exposure to $\mathrm{CO}$ at $100 \mathrm{~K}$.

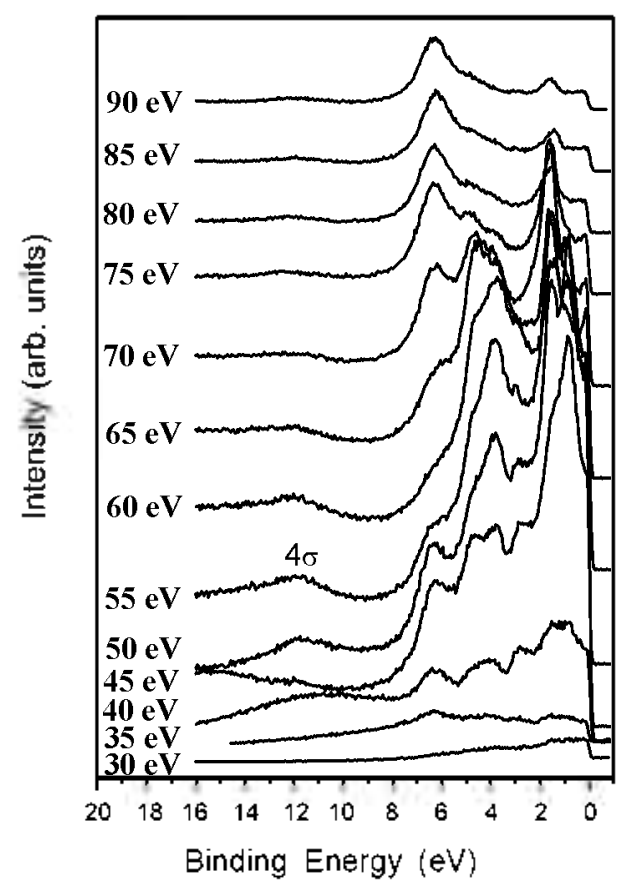

Figure 4. The valence band spectra were collected after heating the sample in Fig. 3 to $900 \mathrm{~K}$. The photon energies used to take the spectra are given in the figure.

different initial coverages from a $\mathrm{Mo}(110)$ surface. Some of the $\mathrm{CO}$ molecules on the $\mathrm{Mo}(110)$ surfaces desorbed below $400 \mathrm{~K}$ ( $\alpha$-state), which corresponds most likely to molecularly' chemisorbed $\mathrm{CO}$. Other desorption states were observed above $900 \mathrm{~K}$. which are referred to as the $\beta-\mathrm{CO}$. In order to examine the desorption characteristics of the $\beta$-state more in detail the Mo(110) surface was exposed to CO at $900 \mathrm{~K}$, and the TDS
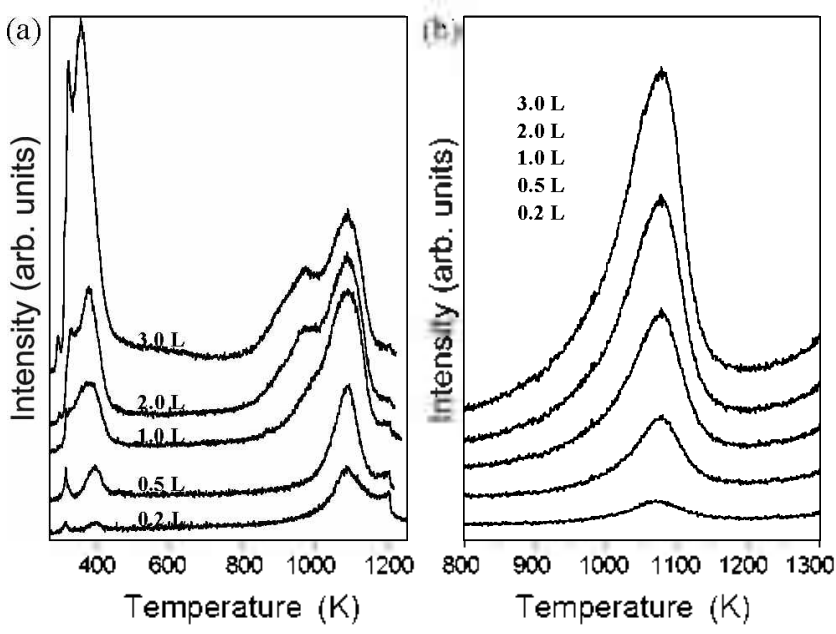

Figure 5. a) TDS spectra of $\mathrm{CO}$ on $\mathrm{Mo}(1 \mathrm{l} 0)$. CO was exposed at room temperature b) TLS spectra of $\mathrm{CO}$ on $\mathrm{Mo}(110)$. The samples were exposed to $\mathrm{CO}$ at $900 \mathrm{~K}$. CO exposures are given in the figure. $(\mathrm{L}=$ torr $\times$ sec. $)$

spectra were collected (Fig. 5b). There was no change in the peak temperature when the amount of $\mathrm{CO}$ exposure was increased. which is indicative of first-order desorption. The asy mmetric peak shape also indicates a first-order desorption of $\mathrm{CO}$. which suggests a non-dissociative chemisorption of $\mathrm{CO}$ on $\mathrm{Mo}(110)$ surfaces above $900 \mathrm{~K}$. This result is in contrast to the previous suggestions that $\mathrm{CO}$ is dissociated in the $\beta$-state on Mo( $(10) .{ }^{35}$ Based on the TDS data. CO can be suggested to be molecularly bound the $\beta$-state. Alternatively, it is proposed there should be a substantial attractive interaction between $O$ and $C$ in the $\beta$-state. even when $C O$ is dissociated, such that these atoms can readily recombine to a molecule without surface diffusion and can lead to the first order desorption kinetics.

\section{Conclusion}

Using SRPES, the CO chemisorption structure on Mo( 110$)$ is quite similar to that on W(110) surfaces. The CO-induced peak centered at $12 \mathrm{eV}$ below the Fermi level was observed in the valence level spectra after heating the $\mathrm{CO} / \mathrm{Mo}(110)$ sample to $900 \mathrm{~K}$. which can be attributed to the $4 \sigma$-state of $\mathrm{CO}$, or $2 \mathrm{~s}$ of dissociated $\mathrm{C}$. TDS shows a first order desorption of CO above $900 \mathrm{~K}$. implying that there should be formation of molecularly bound $\mathrm{CO}$ or a substantial attractive interaction between $\mathrm{O}$ and $\mathrm{C}$ above $900 \mathrm{~K}$.

Aclonowledgments. This study was supported by the SRC program (CNNC) of MOST/KOSEF (grant R11-2001-091$00000-0$ ). The support from the BK 21 project of Ministry of Education Korea, is gratefully acknowledged. The experiments at PLS were supported in part by MOST and by Dr. $\mathrm{Ki}$-jeong Kim and Dr. Bongsoo Kim

\section{References}

1. Masel, R. I. Principles of Adsontion and Reaction on Solid Sufaces: John Wiley \& Sons, Inc: New York, 1996. 
2. Handbook of Heterogeneous Catalysis: Ertl, G.; Knoezinger. H.: Schueth, F.; Weitkamp, T., Eds: Wiley VCH Verlag GmbH \& Co.: Weinheim, 2008.

3. Yates, Jr., T. T. Sirf. Sci. 1994, 299, 731-741.

4. Campuzano, J. C. The Adsorption of Carbon Monoxide bv Transition Metals: The Chemical Physics of Solid Surfaces and Heterogeneous Catalysis; King D. A.: Woodruff, D. P., Eds.; Elservier: Amsterdam, 1990; Vol. 3, Part A3.

5. Young, D. L.; Gomer, R. Surf. Sci. 1974, 4t, 277-280.

6. Viswanath, Y.: Schunidt, L. D. J. Chem. Phvs. 1973, 59, $4184-$ 4191 .

7. Anders, L. W.; Hansen, R. S. J. Chem. Phys. 1975, 62, 46524660 .

8. Yates, Jr., I. T.: King, D. A. Surf. Sci. 1972, 30,601-616.

9. Yates, J.. I. T.: King, D. A. Surf. Sci. 1972, 32, 479-505.

10. Viswanath, Y.: Sclunidt, L. D. J. Chem. Phvs. 1973, 59, 41844191 .

11. Houston, J. E.: Madey, T. E. Phn's. Rev B 1982, 26, 554-566.

12. Lem1g, C.: Vass, M.; Gomer, R. Surf. Sci. 1977, 66, 67-100.

13. King, D. A.: Govmour, C. G.; Yates, J., I. T. Proc. R. Soc. Lond. A $1972,331,361-376$

14. Steinbruchel, Ch.: Gomer, R. Surf. Sci. 1977, 67, $21-44$.

15. Yates, Jr., T. T.: Madey, T. E.: Erickson, N. E. Suff Sci. 1974, 13, 257-274.

16. Guillot, G.; Riwan, R.; Lecante, T. Swf. Sci. 1976, 59, 581-592.

17. Semancik, S. P.; Estrup, J. Suff. Sci. 1981, 104, 26-28.

18. Atkinson, T: Brundle, C. R, Roberts, M. W. Faraday Discuss. Chem. Soc. 1974, 58, 62-79.
19. Umbach, E.: Fuggle, T. C.: Menzel, D. J. Electron Spec. and Rel. Phenom. 1977, 10, 15-34.

20. Umbach. E.: Menzel. D. Surf. Sci. 1983.135. 199-224.

21. Houston, J. E. Surf. Sci. 1991, 255, 303-308.

22. Froitzheim, H.: Thach. H.: Lehwald. S. Surf. Sci. 1977, 63. 56-66.

23. Yang, T.S.: Jee, H.-G.; Boo, J-H.: Han, H. S.: Lee, G. H.; Kim, Y. D.: Lee. S.-B. Bull. Kor Chem. Soc. 2008. 29. $1115-1120$.

24. Kim, Y. D.; Boo, T.-H.; Lee, S.-B. Surf. Sci. 2009 doi : $10.1016 /$ j.Susc 200809.053

25. Christmann, K. Introduction to Surface Phusical Chemisny, Steinkopff Verlag: Darmstadt,1991

26. Eastman, D. E.; Cashion, K. Phys. Rev: Lett. 1971, 27, 15201523.

27. Fuggle, I. C.: Steinkilberg, M.: Menzel, D. Chem. Phws. 1975, 11. 307-317.

28. Allyn, C. L.: Gustafsson, T.: Plummer, E. W. Sold State Commu. $1977,24,531-534$

29. Davenport, J. W. Phvs. Rev Lett. 1976, 36, 945-949.

30. Smith, R. I.; Anderson, J. A.: Lepeyre, G. J. Phws Rev Letr. 1976, 37, 1081-1084.

31. Shinn, N. D.; Madey, T. E. Phys. Rev B 1986, $33,1464-1467$.

32. Shim, N. D. Phw Rew B 1988, 38, 12248-12258.

33. Mehandru, S. P.: Anderson, A. P. Surf. Sci. 1988, 201, 345-360.

34. Choe, S. J.: Kang, H. I.; Park, D. H.; Huh, D. S.: Lee, S.-B. Bull. Kon Chen Soc. 2004, 25, 1314-1320.

35. Jaworowshi, A. . .; Smedh, M.; Borg, M.; Sandell, A.; Beutler, A.; Sorensen, S. L.; Lundgren, E; Andersen, J. N. Surf. Sci. $2001,+92,185-194$. 